\title{
Experimental studies on pore size change of porous ceramic membranes after modification
}

\author{
Y.S. Lin ${ }^{a, *}$ and A.J. Burggraaf ${ }^{\text {h }}$ \\ ${ }^{\mathrm{A}}$ Department of Chemical Engineering, University of Cincinnati, Cincinnati, OH 45221 (USA) \\ ${ }^{\mathrm{b}}$ Laboratory of Inorganic Chemistry, Materials Science and Catalysis, University of Twente, 7500 AE Enschede \\ (The Netherlands)
}

(Received August 13, 1992; accepted in revised form December 17, 1992)

\begin{abstract}
Experimental results on pore size change of a microfiltration (MF) $\alpha$-alumina membrane and an ultrafiltration (UF) $\gamma$-alumina membrane after modification by chemical vapor deposition (CVD) of solid oxides in the membrane pores are presented and explained using the results of a theoretical analysis. With an approx. 10-fold reduction in permeability, the average pore size of the MF membrane is found to increase after CVD modification, due to its relatively broader initial pore size distribution with a small amount of large pores and due to the particular CVD conditions (heterogeneous deposition mechanism) which give a pore narrowing rate independent of pore size. The effective pore size of the UF membrane appears to remain unchanged after modification with an approx. 50-fold reduction in permeability, as a result of the slit-shaped pores of the $\gamma$-alumina film and the particular modification conditions. The experimental and theoretical results suggest that, in order to reduce effectively the average pore size of a membrane by a modification process, the membrane should have a rather uniform pore size distribution, or the modification process should be conducted under conditions which give a pore narrowing rate proportional to the pore size.
\end{abstract}

Keywords: ceramic membranes; gas separations; membrane preparation and structure; membrane modification, pore size change

\section{Introduction}

The recent development of ceramic membranes with high thermal, chemical and structural stability and ability of having catalytic properties has opened up new horizons for membrane applications. Of particular interest are the potential applications of ceramic membranes in high temperature gas separations and catalytic reactions. Important to these appli-

*To whom correspondence should be addressed. cations are the preparation of ceramic membranes with a tailor-designed pore size and desired surface chemical properties. Several methods, including the relatively well-developed sol-gel method, have been used to fabricate microfiltration, ultrafiltration (pore size from $0.1 \mu \mathrm{m}-2 \mathrm{~nm}$ ) and microporous (pore size $<2 \mathrm{~nm}$ ) ceramic membranes [1-4]. Nevertheless, the ceramic membranes prepared by these methods have a pore size and structure fixed by its preparation method. For example, $\gamma-\mathrm{Al}_{2} \mathrm{O}_{3}$, $\mathrm{TiO}_{2}$ or $\mathrm{ZrO}_{2}$ membranes prepared by the sol- 
gel method (via the particulate sol route) have a pore size of 2-4 $\mathrm{nm}$ [5-7]. Microporous silica membranes can be directly prepared by the solgel method (via the polymeric sol route) $[3,8]$, phase-separation method [4] and CVD method [9].

Currently, the best-studied porous ceramic membrane is the commercially available UF $\gamma$ $\mathrm{Al}_{2} \mathrm{O}_{3}$ membrane with a pore size in the range of 3-4 $\mathrm{nm}$. Since direct preparation of porous ceramic membranes with a pore size smaller than $2 \mathrm{~nm}$ is difficult, many investigators have recently focused on modification of the available ceramic membranes (especially the 3-4 nm pore size $\gamma-\mathrm{Al}_{2} \mathrm{O}_{3}$ membrane) in order to increase the permselectivity by reducing pore size, plugging pinholes or modifying the surface chemical properties [10-18]. Table 1 summarizes recently reported studies on the modification of porous ceramic membranes focusing on varying the pore size or modifying the surface properties for the improvement of permselectivity.

Various methods have been successfully em- ployed to vary the pore size of zeolite materials, as reviewed exclusively in a recently published book [19]. For example, the pore opening of zeolite ZSM- 5 could be reduced by chemical vapor deposition (CVD) of an ultrathin silica layer on the external surface of the zeolite crystals [20]. As summarized in Table 1, studies on modifying ceramic membranes have also been reported recently [10-18]. Methods used to modify ceramic membranes can be categorized into the vapor phase approach and the liquid phase approach. In both approaches precursors are introduced into the pores of a porous ceramic membrane and, in most cases, after a chemical reaction process a solid is formed and deposited on the internal pore surface of the membrane. One of the vapor phase methods for ceramic membrane modification is the counterdiffusion CVD method, which involves counterdiffusion of two vapor precursors in the membrane pores and CVD of a solid product on the pore surface $[9,13,14]$. This is basically a method extended from the electrochemical vapor deposition originally developed by West-

\section{TABLE 1}

Recent studies concerning modification of ceramic membrane pore size for improving permselectivity

\begin{tabular}{|c|c|c|}
\hline Investigators & Membranes modified & Modification method \\
\hline Okubo and Inoue (1989) & One-layer porous glass & Deposition of $\mathrm{SiO}_{2}$ from \\
\hline$[10]$ & membranes & TEOS vapor \\
\hline Lin et al. (1990) & One-layer $\alpha$-alumina membranes & $\mathrm{CVD}$ of $\mathrm{Y}_{2} \mathrm{O}_{3} / \mathrm{ZrO}_{2}$ from \\
\hline$[30]$ & Two-layer zirconia membranes & $\mathrm{YCl}_{3} / \mathrm{ZrCl}_{4}$ and $\mathrm{H}_{2} \mathrm{O}$ vapors \\
\hline Miller and Koros (1990) & Supported $\gamma$-aluminạ membranes & Chemical deposition of TDFS \\
\hline [11] & supplied by Alcoa & (organometallic) \\
\hline Ma et al. (1991) & Supported $\gamma$-alumina membranes & Incipient wet-impregnation of \\
\hline$[12]$ & supplied by Alcou & $\mathrm{Fe}_{2} \mathrm{O}_{3}$ and $\mathrm{Al}_{2} \mathrm{O}_{3}$ \\
\hline Kitao and Asaeda (1991) & Supported silica membranes & CVD of $\mathrm{SiO}_{2}$ from $\mathrm{SiH}_{4}$ vapor \\
\hline [13] & prepared by sol-gel method & and $\mathrm{O}_{2}$ \\
\hline Lin et al. (Alcoa) $(1991,1992)$ & Supported $\gamma$-alumina membranes & CVD of $\mathrm{SiO}_{2}$ and organic \\
\hline$[16-17]$ & (Alcoa) & vapor deposition of carbon \\
\hline Iin and Burggraaf (1992) & One-layer alumina membranes & CVD of $\mathrm{ZrO}_{2}$ from chloride \\
\hline$[14]$ & and La-modified supported & and $\mathrm{H}_{2} \mathrm{O}$ vapors \\
\hline & $\begin{array}{l}\gamma \text {-alumina membranes } \\
\text { Supoorted } \gamma \text {-alumina membranes }\end{array}$ & \\
\hline [18] & supported g-aruma inemoranes & $\mathrm{V}_{2} \mathrm{O}_{5}$ by the reservoir method \\
\hline
\end{tabular}


inghouse for fabrication of solid oxide fuel cells [21]. In another vapor phase method, a vapor precursor (or precursors) is introduced from one of the membrane surfaces into the membrane pores and deposited (possibly after a chemical reaction) on the membrane pore surface $[10,11,17]$. This vapor phase method is very similar to the better-studied chemical vapor infiltration (CVI) method for fabrication of ceramic matrix composites [22]. In the liquid phase approach, a small amount of impregnating solution containing solid precursor (s) is sucked into the membrane pores by capillary force. The solid remains on the internal pore surface after the solvent has dried $[12,15,18]$. In modifying porous $\gamma-\mathrm{Al}_{2} \mathrm{O}_{3}$ thin films supported on a larger pore $\alpha$-alumina layer, Uhlhorn et al. [18] developed a so-called reservoir method in which drying of the solvent takes place only on the surface of the $\gamma-\mathrm{Al}_{2} \mathrm{O}_{3}$ film. Because of the large amount of the solution contained in the $\alpha$-alumina support, this method allows impregnation of large amount of solid in the thin $\gamma-\mathrm{Al}_{2} \mathrm{O}_{3}$ film.

Unlike zeolites, porous ceramic membranes normally have a pore size distribution (PSD) and a noncircular shaped pore opening. Some ceramic membrane samples may contain pinholes or defects which constitute a small portion of the larger pores in the PSD of the membrane samples. Deposition of a solid product into zeolite pore openings will certainly result in a reduction in the pore size because zeolites have a uniform PSD and near-circular shaped pore opening (e.g. ZSM-5). However, experimental results of some of the previous studies on modification of porous ceramic membranes seem to suggest that the deposition of a solid in ceramic membrane pores does not necessarily always result in a reduction of the average pore size, or in an improved permselectivity. In a recent theoretical study [23], Lin found that whether the effective pore size (average pore size) can be reduced by depositing a solid in membrane pores depends on the initial PSD and pore narrowing kinetics. The objectives of the present paper are to present the experimental results on the pore size change of porous ceramic membranes after modification and to explain these experimental findings with the results of the theoretical analysis.

\section{Determination of ceramic membrane pore size}

Ceramic membranes after modification usually have an asymmetric structure because of the non-uniform deposition of deposited species along the gas diffusion direction across the membrane [14] (as schematically shown in Fig. 1). For a membrane after modification we can define the region of the membrane where there is no deposit as the support (unmodified zone) and where there is deposit as the modified zone. Experimentally, however, it is difficult to locate the interface between the modified and unmodified zone. As shown in Fig. 1, the pore radius of each pore in the modified zone is not uniform along the gas diffusion direction. Since in most cases the width of the deposition zone

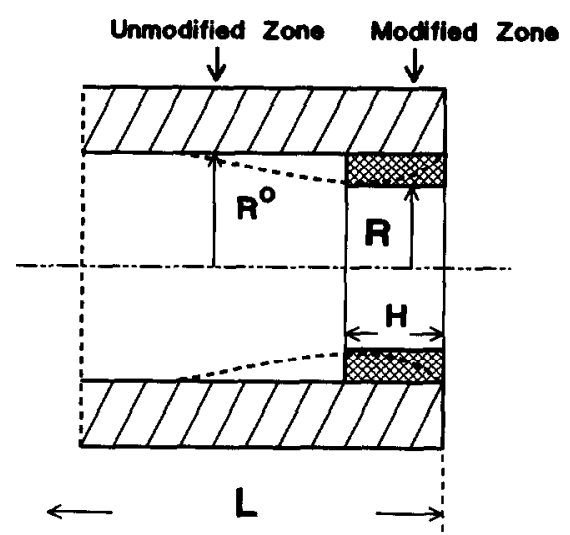

Fig. 1. Distribution of deposit in the membrane pores along the gas diffusion direction (dashed-curves). The deposit distribution curve is averaged to give a rectangular shape (solid lines) which is defined as the modified zone with an average width of $H$ and pore radius of $R$. 
is much smaller than the membrane thickness, it is reasonable that a pore size averaged along the gas diffusion direction in the pore, $R$, is used to designate the pore size for each pore in the modified zone. Corresponding to $R$ an averaged thickness of the modified zone $H$ is defined, as shown in Fig. 1. In some cases $R$ and $H$ for the deposition zone can be calculated from the gas permeation data using the method described next. Pores on the surface of a membrane have a pore size distribution (PSD). The pore size of interest for gas permeation is the average pore size of the modified zone in the membrane.

The most common method for determining the pore size of porous ceramic membranes is adsorption porosimetry $[6-8,9,15,24]$. In this method, the PSD and the average pore size of a membrane sample are calculated from the adsorption or desorption isotherm of nitrogen measured by commercially available adsorption porosimeters. The micropore size of unsupported membranes could also be determined by measuring the equilibrium adsorption of gaseous molecules with different size (the molecular probing method) [25]. However, it is difficult to use these adsorption methods to determine the average pore size of the modified zone of ceramic membranes after modification because of the presence of the unmodified zone. A recently developed dynamic flow technique (permporosimetry) allows determination of the PSD of the supported top-layer or that of the modified zone of ceramic membranes [26,27]. This method is based on the measurements of the flow rate of a gas mixture consisting of a non-condensible gas and a condensible gas through a membrane sample as a function of the vapor pressure of the condensible gas. Since this method requires a complex and sophisticated experimental setup, currently only limited laboratories have the capability of measuring reliable PSD data of porous ceramic membranes by this method.

In this investigation, a simple gas permea- tion method was used to examine the change of the average pore size of ceramic membranes after modification. In this method, a helium flow at a given flow rate $Q$ was passed through a membrane sample (from the modified zone side). After steady-state was reached, an upstream pressure $\left(P_{\mathrm{h}}\right)$ and a downstream pressure $\left(P_{1}\right)$ were measured by pressure meters. The gas permeability was calculated using the following definition:

$$
(F / L)=Q / S_{\mathrm{to}}\left(P_{\mathrm{h}}-P_{\mathrm{l}}\right)
$$

where $L$ is the disk thickness and $S_{\text {to }}$ the total permeation area of the disk. The permeability data at different average pressure $P_{\mathrm{av}}$ $\left[P_{\mathrm{av}}=\left(P_{\mathrm{h}}+P_{1}\right) / 2\right]$ were measured for the membrane before and after modification. The results were plotted as $(F / L)$ versus $P_{\mathrm{av}}$ and regressed with the following linear equation:

$(F / L)=\alpha+\beta P_{\mathrm{av}}$

Experimental values of $(\beta / \alpha)$ for the membrane before modification or after modification are used to examine the change of the average pore size of the modified zone of the ceramic membranes after modification, based on the results of the following theoretical analysis.

For a cylindrical pore with a constant pore size along the gas diffusion direction and a pure non-adsorbable gas, application of the dustygas model gives the permeation flow as:

$$
J_{i}(R)=\left[\alpha_{i}(R)+\beta_{i}(R) P_{\mathrm{av}}\right]\left(P_{\mathrm{h}}-P_{1}\right) S_{i}(R)
$$

where coefficients $\alpha_{i}$ and $\beta_{i}$ are attributed to the Knudsen and viscous flows, respectively, as [15,29]:

$$
\begin{aligned}
& \alpha_{i}(R)=1.06(1 / L)(1 / \tau) R\left(R_{\mathrm{g}} T M\right)^{-1 / 2} \\
& \beta_{i}(R)=0.125(1 / L)(1 / \tau) R^{2} / \mu R_{\mathrm{g}} T
\end{aligned}
$$

$S_{i}(R)$ is the cross sectional area of the pore (for cylindrical pore, $S_{i}(R)=\pi R^{2}$ ). In eqns. (4) and $(5), \tau$ is the tortuosity factor; $T$ the tempera- 
ture, $M$ and $\mu$ the molecular weight and viscosity of the permeating gas, respectively, and $R_{\mathrm{g}}$ the gas constant. For uniform pore membranes, if $\beta$ and $\alpha$ are measured for the modified zone, the pore size $R$ (averaged along the pore diffusion direction ) can be calculated from $\beta / \alpha$, as shown by eqns. (4) and (5). With known $R$ and other parameters in eqn. (4) (except for $H$ ), the corresponding $H$ can be calculated from eqn. (4).

For membranes with a PSD, the permeability $(F / L)$ can be calculated by integrating eqn. (3) over the whole membrane surface with the use of PSD information:

$F / L=\frac{1}{S_{\mathrm{to}}\left(P_{\mathrm{h}}-P_{\mathrm{l}}\right)} \int_{0}^{\infty} J_{i}(R) n(R) \mathrm{d} R$

where $n(R)$ is the number PSD, which can be correlated to the area PSD by [23]:

$P(R)=S_{i}(R) n(R) / S_{\mathrm{po}}$

In eqn. (7) $S_{\mathrm{po}}$ is the total area of the pore opening (cross-sectional area). $P(R) \mathrm{d} R$ has the physical meaning of the ratio of the cross-sectional area of the pores with pore size from $R$ to $(R+\mathrm{d} R)$ to the total area of the pores. $n(R) \mathrm{d} R$ is the number of pores with pore size from $R$ to $(R+\mathrm{d} R)$. Defining the porosity as $\epsilon=S_{\mathrm{po}} / S_{\text {to }}$, inserting eqns. (5) and (7) into eqn. (6) yields eqn. (2). Coefficients $\alpha$ and $\beta$ in eqn. (2) are now correlated by the following equations:

$\alpha=1.06(1 / L)(\epsilon / \tau) R^{\prime}\left(R_{\mathrm{g}} T M\right)^{-1 / 2}$

and

$\beta=0.125(1 / L)(\epsilon / \tau) R^{\prime \prime} / \mu R_{\mathrm{g}} T$

with:

$\boldsymbol{R}^{\prime}=\int_{0}^{\infty} R P(R) \mathrm{d} R$

and

$\boldsymbol{R}^{\prime \prime}=\int_{0}^{\infty} R^{2} P(R) \mathrm{d} R$
For uniform pore membranes, $\boldsymbol{R}^{\prime}=R$ and $\boldsymbol{R}^{\prime \prime}=R^{2}$. For membranes with a PSD, the flowaveraged pore size has been defined as [23]:

$R_{\mathrm{kv}}=\boldsymbol{R}^{\prime \prime} / \boldsymbol{R}^{\prime}$

and from eqns. (8) and (9):

$R_{\mathrm{kv}}=\left[8.47 \mu\left(R_{\mathrm{g}} T / M\right)^{1 / 2}\right](\beta / \alpha)$

which means that $R_{\mathrm{kv}}$ can directly be calculated from the experimentally measurable ratio $(\beta /$ $\alpha$ ). Usually, the smaller the pore size $R_{\mathrm{kv}}$, the more the selective permeation mechanisms (surface diffusion, molecular sieving effect) contribute to the overall permeation, and hence the larger the permselectivity. The theoretical analysis presented above has generalized the previous description for gas permeation through uniform pore membranes $[15,29]$ to that through non-uniform pore membranes.

The above analysis is now extended to composite membranes consisting of two layers with different pore structures (e.g. large pore support and small pore top-layer). One layer membranes after modification also become two-layer composites consisting of an unmodified zone and a modified zone, as shown in Fig. 1. If a two-layer membrane is modified (such as supported $\gamma$-alumina membranes), it can be assumed that the whole thin top-layer is the modified zone because the top-layer is much thinner than the support.

In the previous studies $[14,29]$, a substraction method was used to determine the values of $\beta$ and $\alpha$ for the supported top-layer. This was done by first measuring the permeation data for the support only and then for the support/toplayer composite. The permeability data for the top-layer were calculated by subtracting the permeation data for the support/top-layer composite from that for the support only using a series model. To characterize the modified ceramic membranes this substraction method is complicated by the fact that (1) a small error 
(e.g. difference in the permeation area in the two measurements) introduced in permeation experiments may result in a substantial error in calculating $\beta$ and $\alpha$ for the modified zone (in some preliminary experiments a negative value for $\beta$ was determined for the modified zone) and (2) in many cases the permeation data for the unmodified zone are not available because of the difficulty in locating the unmodified zone.

The following simplified method is therefore used to examine semi-quantitatively the membrane pore size change in this work. This method is based on the fact that the experimentally measured permeability data for most two-layer membrane composites studied in this work could be well fitted with eqn. (2) with $P_{\mathrm{av}}$ being the average of the upstream pressure and downstream pressure. The experimental results will be presented in the Results and Discussion Section. Nevertheless, it is known that theoretically eqn. (2) only applies to homogeneous media. This contradiction will be explained as follows.

For a two-layer system, applying eqn. (2) to the support (or the unmodified zone) and to the top-layer (or the modified zone) gives the following equations correlating the permeation flows to the He pressures at different locations across the membrane sample:

$Q=S\left[\alpha_{\mathrm{t}}+0.5 \beta_{\mathrm{t}}\left(P_{\mathrm{h}}+P_{\mathrm{m}}\right)\right]\left(P_{\mathrm{h}}-P_{\mathrm{m}}\right)$

$\left.Q=S\left[\alpha_{\mathrm{s}}+0.5 \beta_{\mathrm{s}}\left(P_{\mathrm{m}}+P_{1}\right)\right] P_{\mathrm{m}}-P_{1}\right)$

where subscripts " $s$ " and " $t$ " denote coefficients $\alpha$ and $\beta$ for the support and the top-layer respectively. $P_{\mathrm{m}}$ is the pressure at the interface of the two layers and can be found by solving eqns. (14) and (15) as:

$$
\begin{aligned}
P_{\mathrm{m}}=\left[Z^{2}+\right. & 2\left(\alpha_{\mathrm{s}} P_{\mathrm{l}}+\alpha_{\mathrm{t}} P_{\mathrm{h}}+\beta_{\mathrm{s}} P_{1}^{2} / 2\right. \\
& \left.\left.+\beta_{\mathrm{t}} P_{\mathrm{h}}^{2} / 2\right) /\left(\alpha_{\mathrm{g}}+\beta_{\mathrm{t}}\right)\right]^{1 / 2}-Z
\end{aligned}
$$

where

$$
Z=\left(\alpha_{\mathrm{s}}+\beta_{\mathrm{t}}\right) /\left(\beta_{\mathrm{s}}+\beta_{\mathrm{t}}\right)
$$

Substituting eqn. (16) in eqn. (14) or eqn. (15) to eliminate $P_{\mathrm{m}}$, the permeation flow $Q$ is now expressed as a function of $P_{\mathrm{h}}, P_{\mathrm{l}}, \alpha_{\mathrm{s}}, \alpha_{\mathrm{t}}, \beta_{\mathrm{s}}$ and $\beta_{\mathrm{t}}$. To avoid showing the complex final equation, we give the following general form:

$Q=f\left(P_{\mathrm{h}}, P_{\mathrm{l}}, \alpha_{\mathrm{s}}, \alpha_{\mathrm{t}}, \beta_{\mathrm{s}}, \beta_{\mathrm{t}}\right)$

The permeability for the whole two-layer system can be written as:

$$
\begin{aligned}
(F / L)_{\mathrm{av}} & =Q / S_{\mathrm{to}}\left(P_{\mathrm{h}}-P_{\mathrm{l}}\right) \\
& =F\left(P_{\mathrm{h}}, P_{1}, \alpha_{\mathrm{s}}, \alpha_{\mathrm{t}}, \beta_{\mathrm{s}}, \beta_{\mathrm{t}}\right)
\end{aligned}
$$

It is impossible to rearrange eqn. (19) to the same linear form as for eqn. (2):

$$
(F / L)_{\mathrm{av}}=\alpha_{\mathrm{av}}+\beta_{\mathrm{av}}\left(P_{\mathrm{h}}+P_{1}\right) / 2
$$

where $\alpha_{\mathrm{av}}$ and $\beta_{\mathrm{av}}$ are the average permeability coefficients for the whole composite and should not depend on other parameters except for $\beta_{t}$, $\alpha_{\mathrm{t}}, \beta_{\mathrm{s}}$ and $\alpha_{\mathrm{s}}$. Only for a special situation where $\beta_{\mathrm{t}} / \alpha_{\mathrm{t}}=\beta_{\mathrm{s}} / \alpha_{\mathrm{s}}$ (the pore size is the same for the both layers) can eqn. (19) be arranged to the linear form with:

$\alpha_{\mathrm{av}=}\left(1 / \alpha_{\mathrm{t}}+1 / \alpha_{\mathrm{s}}\right)^{-1}$

and

$\beta_{\mathrm{av}}=\beta_{\mathrm{s}} \alpha_{\mathrm{t}} /\left(\alpha_{\mathrm{s}}+\alpha_{\mathrm{t}}\right)$

For more general cases, numerical calculations were performed using eqn. (19) to examine whether the results can be approximated by the linear function eqn. (2). Indeed, in the range of the experimental conditions $\left[P_{\mathrm{av}}=(1-\right.$ 5) $\left.\times 10^{5} \mathrm{~Pa}, P_{1}=1 \times 10^{5} \mathrm{~Pa}\right]$ with different values of $\beta_{s}, \alpha_{t}, \alpha_{s}, \alpha_{t}$, the calculated data of $F / L$ versus $P_{\text {av }}$ could be well fitted by straight lines (regression coefficient $>0.997$ ) and the average coefficients $\alpha_{\mathrm{av}}$ and $\beta_{\mathrm{av}}$ could be determined. This indicates that theoretically the relation of $(F / L)_{\mathrm{av}}$ vs. $P_{\mathrm{av}}$ for the two-layer membranes is indeed also very linear. This is consistent with the experimental findings.

The above analysis suggests a simple way for characterizing the modified membranes. In ex- 
periments, gas permeation data at different average pressures were measured for a membrane sample before and after modification. The values of the average permeation coefficients $\alpha_{\text {av }}$ and $\beta_{\mathrm{av}}$ were regressed from the experimental data using eqn. (20). The value of $\left(\beta_{\mathrm{av}} / \alpha_{\mathrm{av}}\right)$ for the membrane after modification is compared with that before modification. Without using the substraction method, comparison in $\left(\beta_{\mathrm{av}}\right)$ $\alpha_{\text {av }}$ ) for a membrane before and after modification avoids the problem associated with introduction of experimental errors in the two permeation measurements. This is because any systematic errors in the permeation measurements were canceled out by dividing $\beta_{\mathrm{av}}$ with $\alpha_{\mathrm{av}}$. Since the larger the value of $\left(\beta_{\mathrm{av}} / \alpha_{\mathrm{av}}\right)$, the larger the average pore size of the support (or the unmodified zone) and top-layer (or the modified zone), the comparison gives an indication of the change of the pore size of the toplayer or the modification zone. Use of this method is demonstrated in the following Section.

\section{Results and discussion}

\section{Experimental}

Two types of ceramic membranes were modified by depositing $\mathrm{Y}_{2} \mathrm{O}_{3} / \mathrm{ZrO}_{2}$ solid solution in the membrane pores of: (A) a one-layer MF $\alpha$ $\mathrm{Al}_{2} \mathrm{O}_{3}$ membrane with an average pore diameter of about $0.2 \mu \mathrm{m}$ and thickness of $2 \mathrm{~mm}$, and (B) a two-layer ceramic membrane composite consisting of a UF $\gamma-\mathrm{Al}_{2} \mathrm{O}_{3}$ top-layer (average pore radius of $\sim 5 \mathrm{~nm}$ or slit width of $\sim 6 \mathrm{~nm}$; thickness of $\sim 5 \mu \mathrm{m}$ ) and a $\mathrm{MF} \alpha-\mathrm{Al}_{2} \mathrm{O}_{3}$ support (the same as membrane $A$ ). The initial PSDs of the MF membrane A and the UF membrane $B$ are given in Fig. 2. These PSD data were measured using the mercury porosimetry (membrane A) and adsorption porosimetry (from nitrogen desorption isotherm) (membrane B), respectively, and were presented pre-

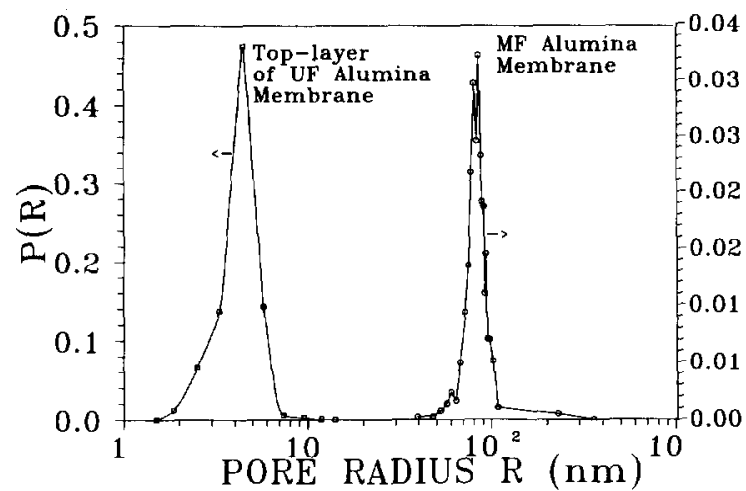

Fig. 2. Area pore size distributions of the MF $\alpha$-alumina membrane and the UF $\gamma$-alumina membrane.

viously in the form of volume PSD [14]. The PSD data presented in Fig. 2 are the area PSDs converted from the volume PSD data previously reported.

Modification was carried out by the counterdiffusion CVD process, as briefly described in the Introduction and detailed in a previously publication [14]. Zirconium/yttrium metal chloride vapor and oxygen/water vapor were used as the vapor precursors in the modification process. As reported in the previous publication [14], for the one-layer MF membrane the solid deposit was present in a small region (20-100 $\mu \mathrm{m})$ near the surface of the membrane exposed to the metal chloride vapor during modification (referred to as the chloride side)]. For the two-layer membranes, the solid was deposited primarily in the top-layer (about $6 \mu \mathrm{m}$ ). This Section will focus on the effects of the modification on the average pore size (permselectivity) and porosity (permeability) of the membranes.

The membrane samples before modification and after modification were characterized by helium adsorption using a gas permeation apparatus. The procedure was described in the previous Section. The permeability data through the whole membrane are plotted versus the average pressure $P_{\mathrm{av}}\left[P_{\mathrm{av}}=\left(P_{\mathrm{h}}+P_{\mathrm{l}}\right) /\right.$ 
2] in Fig. 3 and Fig. 4 for some samples of the both types of membranes before and/or after modification. The permeation data presented in Fig. 3 and Fig. 4 all exhibit a linear relationship, as described by eqn. (20), regardless whether the membrane is a one-layer (membrane $\mathrm{A}$ before modification) or a two-layer membrane (membrane A after modification, or membrane $B$ before or after modification). These experimental results have been ex-

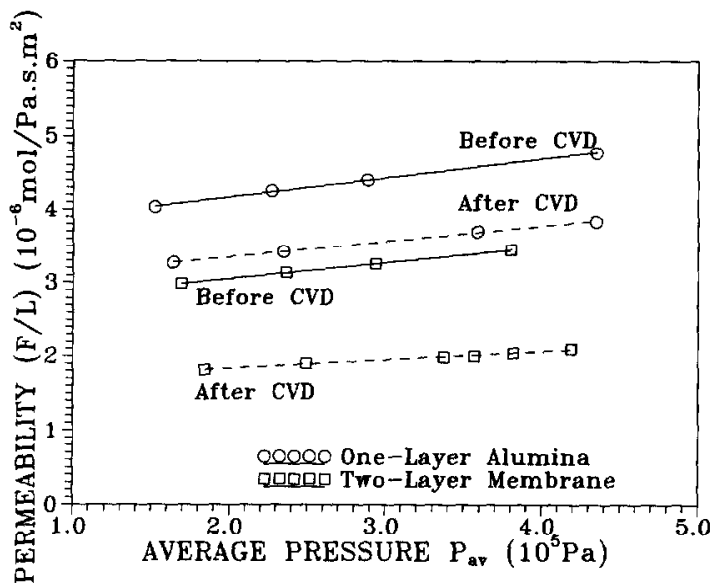

Fig. 3. Permeability of helium through a one-layer MF alumina membrane sample and a two-layer UF alumina membrane sample before and after CVD modification.

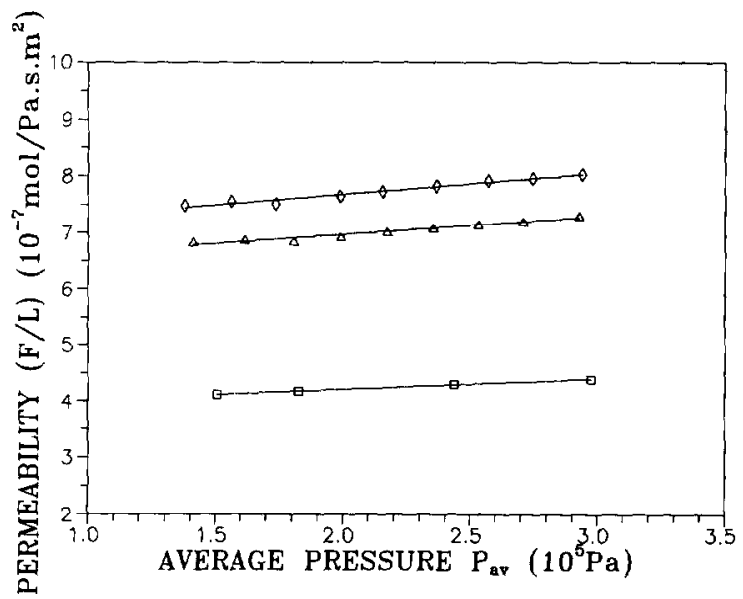

Fig. 4. Permeability of helium through other samples of the UF two-layer ceramic membrane after CVD modification. plained in the previous Section. Values of coefficients $\beta_{\mathrm{av}}$ and $\alpha_{\mathrm{av}}$ were then regressed from the data of permeability versus average pressure for the whole sample, from which values of $\left(\beta_{\mathrm{av}} / \alpha_{\mathrm{av}}\right)$ were calculated. The results are presented in Table 2 for two samples of membrane $A$ and three samples of membrane $B$ before and after the CVD modification.

For both types of membranes, the values of $\alpha_{\mathrm{av}}$ decrease after modification. This is obviously due to the decrease in coefficient $\alpha_{\mathrm{t}}$ for the modified zone of the membranes because of the deposition of the solid solution in the pores. As shown by eqn. (8), the decrease in coefficient $\alpha$ is a result of a reduction in the porosity $\epsilon$ and/or area-related average pore size, $\boldsymbol{R}^{\prime}$, or an increase in the tortuosity factor, $\tau$. Thus, a decrease in the value of $\alpha$ does not provide sufficient information on the pore size change. The change in $(\beta / \alpha)$ is a direct indication of the change in the average pore size, as shown by eqns. (8) $-(13)$.

\section{Results on the one-layer MF membrane}

For the one-layer membrane samples, values of $\left(\beta_{\mathrm{av}} / \alpha_{\mathrm{av}}\right)$ increase after the CVD modification. We now should examine, for the one-layer membrane, whether the increase in $\left(\beta_{\mathrm{av}} / \alpha_{\mathrm{av}}\right)$ is equivalent to an increase in $\left(\beta_{\mathrm{t}} / \alpha_{\mathrm{t}}\right)$, the latter being proportional to the average pore size in the modified zone.

In the calculation results presented below $\alpha_{\mathrm{s}}=3.64 \times 10^{-6}\left(\mathrm{~mol} / \mathrm{Pa}-\mathrm{sec}-\mathrm{m}^{2}\right)$ and $\beta_{\mathrm{s}}=$ $2.59 \times 10^{-12}\left(\mathrm{~mol} / \mathrm{Pa}^{2}-\mathrm{sec}-\mathrm{m}^{2}\right)$ (values for membrane sample \#1 before modification given in Table 2) are used for the unmodified zone of a one-layer membrane. Values of $\alpha_{\mathrm{av}}$ and $\beta_{\mathrm{av}}$ are calculated for the same $\beta_{\mathrm{s}}$ and $\alpha_{\mathrm{s}}$ (because for the unmodified zone they are constant), but different values of $\alpha_{t}$ and $\beta_{t}$ for the modified zone, using the model and method presented in the preceding Section. The calculated $\alpha_{\mathrm{av}}$ and $\left(\beta_{\mathrm{av}} / \alpha_{\mathrm{av}}\right)$ are plotted versus $\alpha_{\mathrm{t}}$ in 
TABLE 2

Experimental values of $\alpha$ and $\beta$ for MF and UF alumina membranes after CVD modification

\begin{tabular}{|c|c|c|c|c|c|c|}
\hline \multirow{2}{*}{$\begin{array}{l}\text { Sample } \\
\text { number }\end{array}$} & \multicolumn{3}{|c|}{$\alpha_{\mathrm{av}}\left(10^{-6} \mathrm{~mol} / \mathrm{m}^{2}-\mathrm{sec}-\mathrm{Pa}\right)$} & \multicolumn{3}{|c|}{$\beta_{\mathrm{av}} / \alpha_{\mathrm{av}}\left(10^{-7} \mathrm{~Pa}^{-1}\right)$} \\
\hline & $\begin{array}{l}\text { before } \\
\text { CVD }\end{array}$ & $\begin{array}{l}\text { after } \\
\text { CVD }\end{array}$ & $\begin{array}{l}\text { change } \\
(\%)\end{array}$ & $\begin{array}{l}\text { before } \\
\text { CVD }\end{array}$ & $\begin{array}{l}\text { after } \\
\text { CVD }\end{array}$ & $\begin{array}{l}\text { change } \\
(\%)\end{array}$ \\
\hline \multicolumn{7}{|c|}{ One-layer MF $\alpha$-alumina membranes } \\
\hline$\# 1^{a}$ & 3.62 & 2.91 & -20 & 7.13 & 7.18 & +0.7 \\
\hline$\# 2^{\mathrm{a}}$ & 2.93 & 1.87 & -36 & 11.3 & 12.3 & +8.7 \\
\hline \multicolumn{7}{|c|}{ Two-layer UF $\gamma$-alumina membranes } \\
\hline$\# 3$ & 2.60 & 1.61 & -39 & 8.22 & 6.95 & -15 \\
\hline$\# 4$ & 1.91 & 0.63 & -67 & 9.79 & 6.54 & -33 \\
\hline \#5 & 2.14 & 0.70 & -67 & 10.5 & 7.1 & -32 \\
\hline
\end{tabular}

The first one-layer $\alpha$-alumina membrane has a slightly smaller pore size than the second one-layer $\alpha$-alumina membrane due to different preparation conditions. The $\alpha$-alumina membrane disks with the pore size the same as the second one were used to prepare the supported $\gamma$-alumina membranes.

Fig. 5 and 6 for the different values of $\Phi$ which is defined as $\left(\beta_{\mathrm{t}} / \alpha_{\mathrm{t}}\right) /\left(\beta_{\mathrm{s}} / \alpha_{\mathrm{s}}\right)$. For a one-layer membrane before modification, $\Phi=1$, meaning that the average pore size of the zone to be modified is the same as that of the unmodified zone before modification.

Figure 5 shows that coefficient $\alpha_{\mathrm{av}}$ decreases with decreasing $\alpha_{\mathrm{t}}$ regardless of the value of $\Phi$. This means that a decrease in the measured $\alpha_{\mathrm{av}}$ for the one-layer membrane after modification is a result of an increase in the permeation resistance in the modified zone. This is obvious

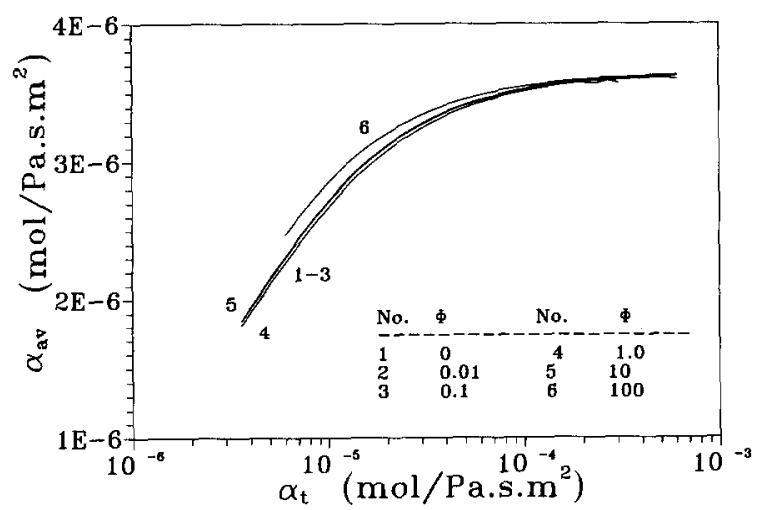

Fig. 5. Calculated $\alpha_{\mathrm{av}}$ vs. $\alpha_{\mathrm{t}}$ for the MF one-layer membrane with a part modified.

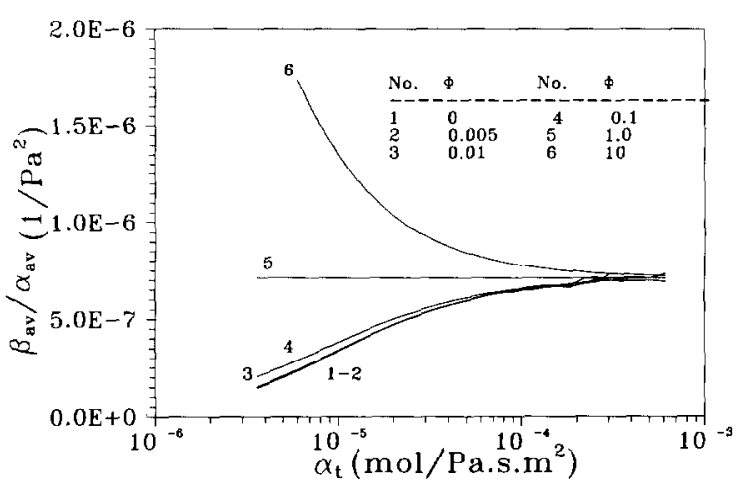

Fig. 6. Calculated $\left(\beta_{\mathrm{av}} / \alpha_{\mathrm{av}}\right)$ vs. $\alpha_{\mathrm{t}}$ for the MF one-layer membrane with a part modified.

because deposition of a solid in the pores always increases the gas permeation resistance. The value of $\left(\beta_{\mathrm{av}} / \alpha_{\mathrm{av}}\right)$ decreases if $\Phi$ is smaller than 1 , or increases if $\Phi$ is larger than 1 , with decreasing $\alpha_{\mathrm{t}}$ due to the deposition of the solid product in the membrane pores. These results suggest that for a one-layer membrane an increase in $\left(\beta_{\mathrm{av}} / \alpha_{\mathrm{av}}\right)$ with a reduction in $\alpha_{\mathrm{av}}$ (i.e. $\alpha_{\mathrm{t}}$ ) after modification corresponds to an increase in $\left(\beta_{t} / \alpha_{t}\right)$ for the modified zone. As 
shown in the preceding Section, $\left(\beta_{t} / \alpha_{t}\right)$ is proportional to the flow-averaged pore size. The experimental results presented in Table 2 for the one-layer membrane (samples \#1 and \#2) show that the flow-averaged pore size of the modified zone has increased after the deposition of solid in the membrane pores.

To further confirm the increase of the average pore size after modification, a helium permeation experiment was conducted for one sample of membrane A before modification, right after CVD modification and after modification but with part of the modified zone (chloride side) sanded off. Values of $\alpha_{\mathrm{av}}$ and $\beta_{\mathrm{av}}$ are summarized in Table 3 . For this sample, values of $\left(\beta_{\mathrm{av}} / \alpha_{\mathrm{av}}\right)$ again increase with decreasing $\alpha_{\text {av }}$ after modification (see Cases $A$ and B). Comparing Cases B, C and D, $\alpha_{\mathrm{av}}$ increases and $\left(\beta_{\mathrm{av}} / \alpha_{\mathrm{av}}\right)$ decreases as the membrane gets thinner with part of the modified zone removed. The value of $\left(\beta_{\mathrm{av}} / \alpha_{\mathrm{av}}\right)$ for Case $\mathrm{D}$ (the modified zone may have been completely removed) is the same as that for Case A (before modification). These results show that: (1) the penetration of the solid deposit, at least for this particular sample, can be as deep as $300 \mu \mathrm{m}$ from the chloride side of the membrane, (2) the pore size of the unmodified zone remains unchanged after the CVD modification process (typically at $1000^{\circ} \mathrm{C}$ for $3-6 \mathrm{hr}$ ), and (3) the average pore size in the modified zone increases after modification.
The theoretical results reported in the previous paper [23] are used to explain the fact that the average pore size increases for the onelayer membrane after deposition of solid in its pores. Since the CVD reaction in the CVD modification process follows a Langmuir-Henshelwood mechanism (the heterogeneous reaction mechanism) [14], the pore narrowing kinetics can be roughly expressed as $\mathrm{d} R /$ $\mathrm{d} t=-k$, where $k$ is the pore narrowing rate constant. This means that the pore narrowing rate is independent of the pore size. Using the theoretical model developed in the previous paper [23], the PSD of the modified zone can be simulated as function of deposition time. The results are presented in Fig. 7 in which the four PSD curves correspond to the different deposition times (for constant $k$ ). Curve \#1 is the initial PSD of the membrane $(t=0)$.

From these PSD data, the ratio of the flowaveraged pore size of the membrane after modification $\left[R_{\mathrm{kv}}(t)\right]$ to that before modification $\left(R_{\mathrm{kv}}^{\mathrm{o}}\right)$ can be calculated using the method reported in the previous paper [23]. In Fig. 8 the calculated $\left(R_{\mathrm{kv}} / R_{\mathrm{kv}}^{\circ}\right)$ is plotted versus the permeability reduction ratio $E_{\mathrm{k}}(t)$ (defined as the ratio of the permeation coefficient for the membrane after modification, $\alpha_{t}$, to that before modification $\left.\alpha_{\mathrm{t}}^{\circ}\right)$. Because $\left(R_{\mathrm{kv}}(t) / R_{\mathrm{kv}}^{\circ}\right)$ is equal to the ratio of $\left(\beta_{\mathrm{t}} / \alpha_{\mathrm{t}}\right)$ for the membrane after modification to that before modification $\left(\beta_{\mathrm{t}}^{o} / \alpha_{\mathrm{t}}^{o}\right)$ (see eqn. 13$)$, both $\left(R_{\mathrm{kv}} / R_{\mathrm{kv}}^{o}\right)$ and

\section{TABLE 3}

Helium permeation data for a one-layer $\alpha$-alumina membrane before and after modification

\begin{tabular}{|c|c|c|c|c|c|}
\hline Case & $\begin{array}{l}\text { Thickness } \\
(\mu \mathrm{m})\end{array}$ & $\begin{array}{l}\alpha_{\mathrm{av}} \times 10^{6} \\
\left(\mathrm{~mol} / \mathrm{Pa}-\mathrm{m}^{2}-\mathrm{sec}\right)\end{array}$ & $\begin{array}{l}\beta_{\mathrm{av}} \times 10^{12} \\
\left(\mathrm{~mol} / \mathrm{Pa}^{2}-\mathrm{m}^{2}-\mathrm{sec}\right)\end{array}$ & $\begin{array}{l}\left(\beta_{\mathrm{av}} / \alpha_{\mathrm{av}}\right) \times 10^{6} \\
\left(\mathrm{~Pa}^{-1}\right)\end{array}$ & $\begin{array}{l}R_{\mathrm{kv}} \\
(\mu \mathrm{m})\end{array}$ \\
\hline (A) before CVD & 2325 & 2.93 & 3.32 & 1.13 & 0.133 \\
\hline (B) after CVD & 2325 & 1.87 & 2.30 & 1.23 & 0.145 \\
\hline (C) after CVDa & 2265 & 2.53 & 3.02 & 1.19 & 0.140 \\
\hline (D) after $\mathrm{CVD}^{\mathrm{a}}$ & 1835 & 3.22 & 3.65 & 1.13 & 0.133 \\
\hline (E) modified zone & $\approx 5$ & 152 & 226 & 1.49 & 0.175 \\
\hline
\end{tabular}

Part of the membrane disk at the surface of modified zone has been sanded off. 


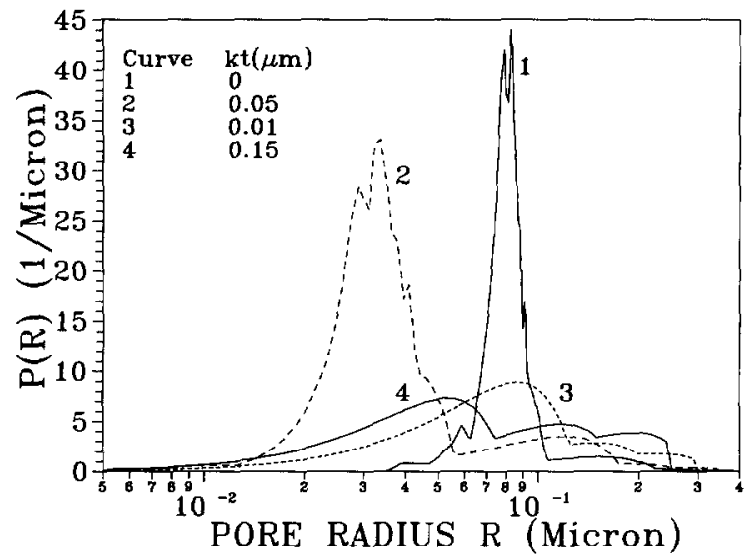

Fig. 7. Simulated pore size distributions of the modified zone of the MF one-layer membrane as a function of modification time.

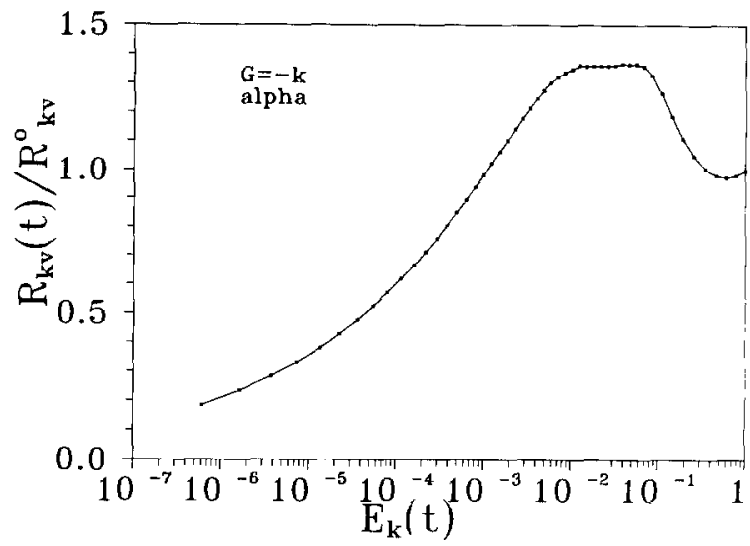

Fig. 8. Calculated average pore size of the modified zone of the MF membrane as a function of the permeability reduction ratio.

$E_{\mathrm{k}}(t)$ are experimentally measurable. Indeed, the simulated results show that for this type of one-layer membranes during the CVD modification process the average pore size increases with decreasing $\alpha_{\mathrm{t}}$. A maximum average pore is reached when $\alpha_{\mathrm{t}}$ is about 50 to 100 times smaller than the original value $\left(E_{\mathrm{kv}}=0.01-0.02\right)$. At this maximum value, the average pore size is about 1.4 time as large as the original average pore size.

Using the data presented in Table 3 and as- suming an average thickness of $5 \mu \mathrm{m}$ for the modified zone, we roughly estimated value of 0.1 for $\alpha_{\mathrm{t}} / \alpha_{\mathrm{t}}^{\mathrm{o}}$, which indicates a ten-fold reduction in permeability, and of 1.3 for $\left[\left(\beta_{t} / \alpha_{t}\right) /\right.$ $\left(\beta_{\mathrm{t}} / \alpha_{\mathrm{t}}\right)^{\circ}$ ] (see Case $\mathrm{E}$ in Table 3). The simulation results in Fig. 8 give also a value of ca. 1.3 for $R_{\mathrm{kv}}(t) / R_{\mathrm{kv}}^{\mathrm{o}}$ at $E_{\mathrm{k}}(t)$ equal to 0.1 . The experimental results are consistent with the theoretical prediction. As analyzed in detail in the previous paper [23], the increase in the average pore size of the one-layer membrane after deposition of solid in its pores is due to its broader initial PSD and the pore narrowing kinetics which gives a pore size independent pore narrowing rate. As the solid is deposited in the membrane pores, the smaller pores are narrowed quicker than the larger pores and the average pore size shifts to a larger value. In these cases the average pore size of membranes would decrease only after the permeability (porosity) is substantially reduced.

\section{Results on the two-layer UF membranes}

For the two-layer membrane (samples \#3, 4,5 in Table 2), $\alpha_{\text {av }}$ decreases by ca. $40-70 \%$, showing deposition of the solid in the pores of the top-layer. Values of $\left(\beta_{\mathrm{av}} / \alpha_{\mathrm{av}}\right)$ also drop by 15-33\% after CVD. Previously it was thought that these results mean a pore size reduction of the top-layer [14]. Nevertheless, we should first examine whether in these cases a decrease in $\left(\beta_{\mathrm{av}} / \alpha_{\mathrm{av}}\right)$ is equivalent to a decrease in $\left(\beta_{\mathrm{t}} / \alpha_{\mathrm{t}}\right)$ for the top-layer in which the solid is deposited. Calculation similar to the cases of one-layer membranes was also made with coefficients $\alpha$ and $\beta$ given in Table 4 for the support (the unmodified zone) and the top-layer (the modified zone). It should be noted that before modification the pore size of the top-layer is smaller than the support, as reflected by the value of $\beta^{\circ} / \alpha^{\circ}$ in Table 4. With unchanged $\beta_{\mathrm{s}}$ and $\alpha_{\mathrm{s}}$ for the support, values of $\alpha_{\mathrm{av}}$ and $\beta_{\mathrm{av}}$ are calculated for the two-layer membrane with a top-layer of 


\section{TABLE 4}

Values of $\alpha$ and $\beta$ for support and top-layer of a two-layer $\gamma$-alumina membrane used for calculation of $\alpha_{\mathrm{av}}$ and $\beta_{\mathrm{av}}$

\begin{tabular}{llll} 
& $\begin{array}{l}\alpha^{o} \\
\left(10^{-6} \mathrm{~mol} /\right.\end{array}$ \\
& $\begin{array}{l}\beta^{\circ} \\
\left(10^{-12} \mathrm{~mol} / \mathrm{m}^{2}-\mathrm{sec}\right)\end{array}$ & $\begin{array}{l}\beta^{\circ} / \alpha^{\circ} \\
\left(10^{-6} \mathrm{~Pa}^{-1}\right)\end{array}$ \\
\hline Support & 3.64 & 2.59 & 0.712 \\
Top-layer & 10.0 & 0.820 & 0.082 \\
\hline
\end{tabular}

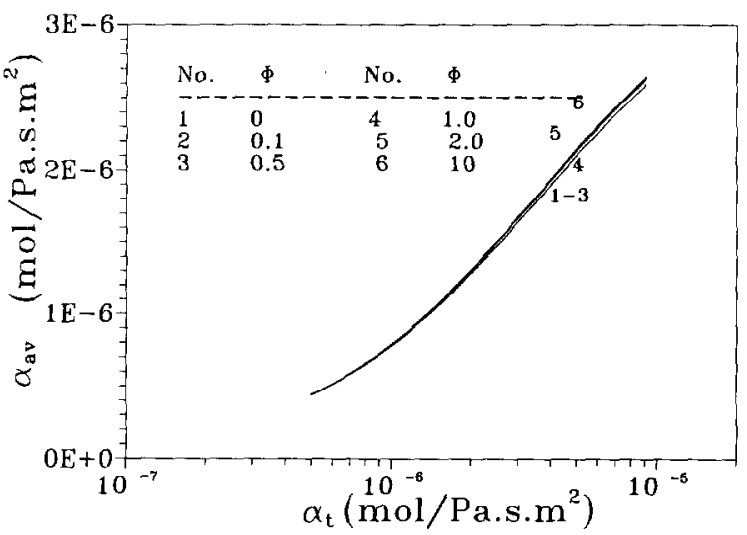

Fig. 9. Calculated $\alpha_{a v}$ vs. $\alpha_{t}$ for the UF two-layer membrane with the top-layer modified.

different $\alpha_{\mathrm{t}}$ (in the range of $\alpha_{\mathrm{t}}$ smaller than $\alpha_{\mathrm{t}}^{\mathrm{o}}=5.00 \times 10^{-7} \mathrm{~mol} / \mathrm{Pa}-\mathrm{sec}-\mathrm{m}^{2}$ ) and $\beta_{\mathrm{t}}$. The results are plotted as $\alpha_{\mathrm{av}}$ and $\left(\beta_{\mathrm{av}} / \alpha_{\mathrm{av}}\right)$ versus $\alpha_{\mathrm{t}}$ in Fig. 9 and Fig. 10 for different values of $\Phi$ which is defined slightly different from the cases of one-layer membranes as: $\Phi=\left(\beta_{t} / \alpha_{t}\right) /$ $\left(\beta_{\mathrm{t}}^{o} / \alpha_{\mathrm{t}}^{\mathrm{o}}\right)$.

Similar to the results given in Fig. 5, $\alpha_{\mathrm{av}}$ decreases with decreasing $\alpha_{t}$, indicating that the total resistance increases with increasing resistance in the top-layer as a result of the deposition of solid in its pores. Similarly the six curves are essentially identical. The values of $\beta_{\mathrm{t}}$ do not influence $\alpha_{\mathrm{av}}$. In fact, all curves presented in Figs. 5 and 9 can be approximated by eqn. (20) which shows that $\alpha_{\mathrm{av}}$ is a function of only $\alpha_{\mathrm{s}}$ and $\alpha_{\mathrm{t}}$.

In contrast to Fig. 6 , the results presented in Fig. 10 show that $\left(\beta_{\mathrm{av}} / \alpha_{\mathrm{av}}\right)$ for the two-layer

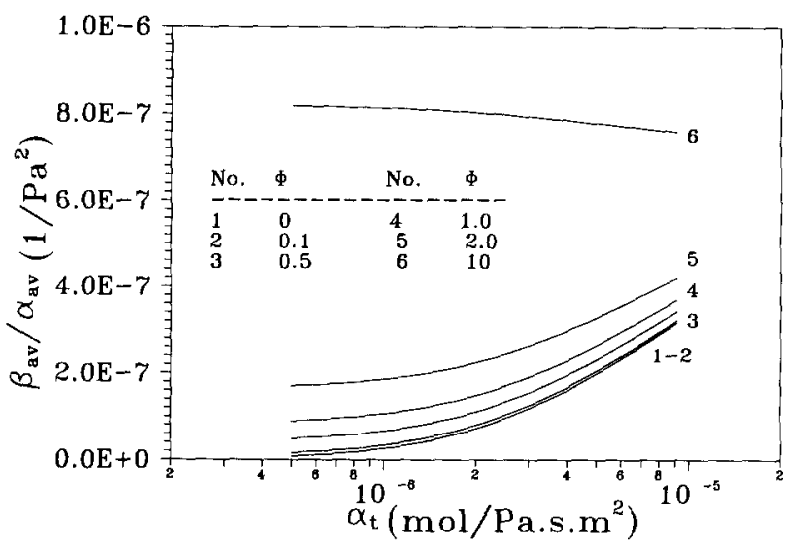

Fig. 10. Calculated $\left(\beta_{\mathrm{av}} / \alpha_{\mathrm{av}}\right)$ vs. $\alpha_{\mathrm{t}}$ for the UF two-layer membrane with the top-layer modified.

membrane substrate decreases with increasing resistance of the top-layer even when $\Phi$ is larger than 1 (curves \#4 and \#5). In other words, a decrease in $\left(\beta_{\mathrm{av}} / \alpha_{\mathrm{av}}\right)$ for the two-layer membrane after modification does not necessarily mean a decrease in the pore size of the top-layer. This can be understood by looking at the simpler case where the pore size of the top-layer is constant when $\alpha_{\mathrm{t}}$ is reduced (curve \#4 in Fig. 10). For this particular case, the initial value of $\left(\beta_{t}^{o} / \alpha_{t}^{o}\right)$ is about $1 / 10$ of that for the support. When $\alpha_{t}$ is larger, indicating a relatively smaller resistance of the top-layer, $\left(\beta_{\mathrm{av}} / \alpha_{\mathrm{av}}\right)$ is closer to the value for the support, i.e. $\left(\beta_{\mathrm{s}} / \alpha_{\mathrm{s}}\right)$. When $\alpha_{\mathrm{t}}$ gets smaller with an unchanged $\left(\beta_{\mathrm{t}} / \alpha_{\mathrm{t}}\right)$ $\left.\left[=\beta_{\mathrm{t}}^{\mathrm{o}} / \alpha_{\mathrm{t}}^{\mathrm{o}}\right)\right]$, the resistance of the top-layer increases. Thus the average value for $\left(\beta_{\mathrm{av}} / \alpha_{\mathrm{av}}\right)$ comes closer to the value for the top-layer $\left(\beta_{\mathrm{t}}^{\mathrm{o}} / \alpha_{\mathrm{t}}^{\circ}\right)$, which is about $1 / 10$ of $\left(\beta_{\mathrm{s}} / \alpha_{\mathrm{s}}\right)$.

In previous work [14], it was considered that the results presented in Table 2 for the twolayer UF membrane samples indicate a reduction of the top-layer after modification. The analysis presented here shows that this is not necessarily true. Thus, the pure helium permeability data presented in Table 2 are not sufficient to examine whether the average pore size of the top-layer of the two-layer membrane has 
been reduced after modification. Other data, such as permselectivity data of the two different gases should be used to examine the pore size change after modification.

Table 5 shows the experimentally measured permeability (at very low average pressure) and ideal separation factor of helium over $\mathrm{O}_{2}$ or $\mathrm{CO}_{2}$ for the two-layer supported $\gamma$-alumina membranes before and after modification. The membrane top-layers have an average pore diameter (slit-width) of about $6 \mathrm{~nm}$ and are supported by the MF membrane A. The experimental separation factor for the samples before modification is slightly smaller than that calculated based the Knudsen diffusivity ( $\alpha_{\text {Knud }}$ for $\mathrm{He} / \mathrm{O}_{2}$ and $\mathrm{He} / \mathrm{CO}_{2}$ are 2.83 and 3.32 respectively). This is because in the studied twolayer membrane samples the large-pore support forms ca. $50 \%$ of the overall gas transport resistance and the contribution of non-separative laminar flow in the support may lower the average separation factor. The improvement of the separation factor of the two-layer membrane after CVD modification is minor (still smaller than the Knudsen values). However, the permeability of the top-layer has been reduced ca. 50 times after modification, which lowers the contribution of the non-separative

TABLE 5

Effects of modification on permeation flux and separation factor for the two-layer $\gamma$-alumina membranes

\begin{tabular}{|c|c|c|c|}
\hline \multirow{2}{*}{$\begin{array}{l}\text { Membrane samples } \\
\text { Sample \# } 1\end{array}$} & \multicolumn{2}{|c|}{$\begin{array}{l}\text { Permeability at } P_{\mathrm{av}}=0 \\
\left(\alpha_{\mathrm{av}}\right) \\
\left(10^{-6} \mathrm{~mol} / \mathrm{m}^{2}-\mathrm{sec}-\mathrm{Pa}\right)\end{array}$} & \multirow[t]{2}{*}{$\begin{array}{l}\text { Exptl. } \\
\text { selectivity }\end{array}$} \\
\hline & $\mathrm{He}$ & $\mathrm{O}_{2}$ & \\
\hline before modification & $3.68(12.2)^{\mathrm{n}}$ & 1.34 & 2.74 \\
\hline after modification & $0.93(1.10)$ & 0.329 & 2.82 \\
\hline Sample \#2 & $\mathrm{He}$ & $\mathrm{CO}_{2}$ & \\
\hline before modification & $4.26(14.2)$ & 1.337 & 3.18 \\
\hline after modification & $0.23(0.23)$ & 0.070 & 3.27 \\
\hline
\end{tabular}

"Data in parenthesis are permeability for the modified zone (toplayer). laminar flow. This indicates that steric effects have not been observed for the modified $\gamma$-alumina top-layer even though the porosity was substantially reduced.

Miller and Koros [11] also reported that the ideal $\mathrm{He} / \mathrm{H}_{2}$ separation factor for the $\gamma$-alumina membrane (from Alcoa) (slit-width of ca. $3 \mathrm{~nm}$ ) after depositing an organometallic compound in its pores improves slightly only after the permeability of helium was reduced ca. 130 times. Similar results were also reported by Lin et al. for the Alcoa membranes [16]: in order to reduce the pore-size of the $\gamma$-alumina toplayer by a factor of 2 the permeability of the top-layer has to decrease by a factor of ca. 150 . These results suggest that the (effective) pore size of the $\gamma$-alumina membrane may not have been reduced by the deposition of solid in its pores unless the porosity of the membrane layer is significantly reduced. If a cylindrical pore shape was assumed for the $\gamma$-alumina pores, permeability would be proportional to $R^{3}$ and a reduction in permeability by a factor of 150 should be equivalent to a reduction in the pore size by a factor of ca. 5 .

First, we should examine the effects of the initial PSD of the $\gamma$-alumina membrane. Using the same method as for the one-layer membrane, PSDs for the $\gamma$-alumina membranes after different modification times were calculated assuming pore narrowing kinetics of $\mathrm{d} R$ / $\mathrm{d} t=-k$ and the initial PSD shown in Fig. 2. The results are presented in Fig. 11 and Table 6. The calculations show that for the $y$-alumina membrane with the initial PSD given in Fig. 2 and the deposition kinetics of $\mathrm{d} R / \mathrm{d} t=-k$, the deposition of solid in the pores will result in a reduction in the average pore size.

It is known that the $\gamma$-alumina membrane has slit-shaped pores which are formed by packing of the plate-shaped $\gamma$-alumina crystallites [5], as shown in Fig. 12(a). A typical $\gamma$-alumina membrane has a slit-length $b$ of about $25 \mathrm{~nm}$ and width $2 R^{\circ}$ of about $3 \mathrm{~nm}$. The slit width 


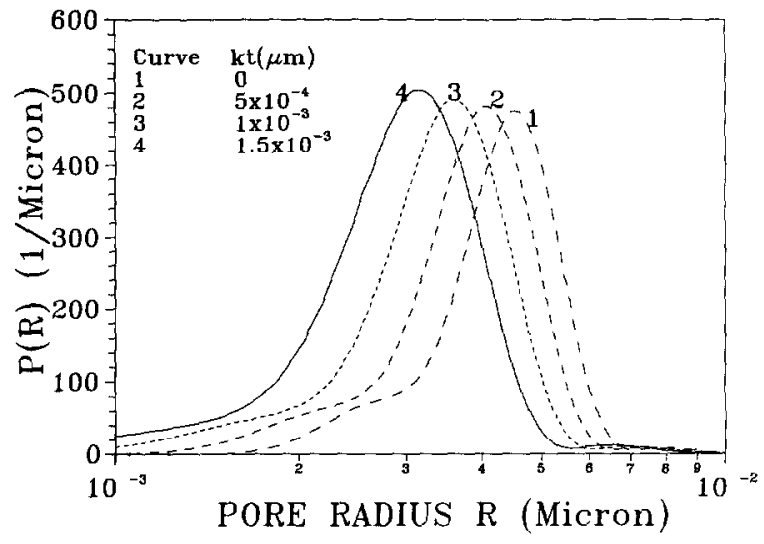

Fig. 11. Simulated pore size distributions of the top-layer of the UF two-layer membrane as a function of modification time (cylindrical pores are assumed).

\section{TABLE 6}

Calculated permeability reduction ratio and average pore size for the $\gamma$-alumina membrane assuming cylindrical pores

\begin{tabular}{lll}
\hline$k t(\mu \mathrm{m})$ & $E_{\mathbf{k}}$ & $R_{\mathbf{k v}}(\mu \mathrm{m})$ \\
\hline 0 & 1 & $4.77 \times 10^{-3}$ \\
0.0005 & 0.706 & $4.37 \times 10^{-3}$ \\
0.001 & 0.479 & $3.96 \times 10^{-3}$ \\
0.0015 & 0.310 & $3.60 \times 10^{-3}$ \\
\hline
\end{tabular}

determines the diffusivity (permselectivity) of a gas, while both the slit length and width contribute to the porosity (permeability). Therefore $R^{\circ}$ or $R$ shown in Fig. 12 is referred to here as effective pore size. During a modification process, one possibility is that the solid species deposits on the pore surface in such a manner as to reduce the total internal pore surface area thereby minimizing the surface energy. In the initial stage of the modification process, the pores might be narrowed in the slit-length direction, until a circular or a near-circular pore with a pore radius equal to the half slit-width is formed, as shown in Fig. 12(b). Consequently, the effective pore size may not change in the initial stage although the pore opening area is significantly reduced. (a)

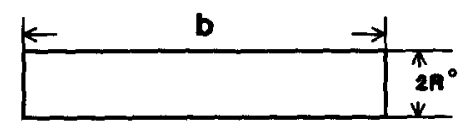

(b)

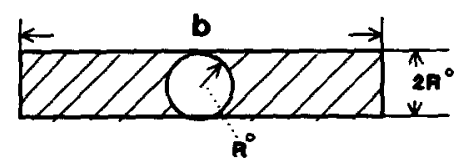

(a)

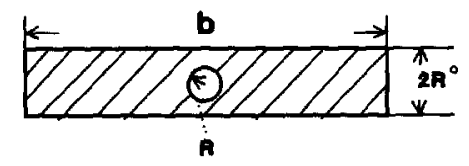

Fig. 12. Schematic representation of a pore narrowing process for a ceramic membrane with slit-shaped pores. The pore is narrowing initially in the slit-length direction (b) and then in the radial direction (c).

Further modification would result in a reduction in the effective pore size, as shown in Fig. 12 (c). With the geometry given in Fig. 12, it is possible to derive the following relation correlating permeability reduction ratio $E_{\mathrm{k}}$ and the effective pore size reduction ratio $\left(R / R^{\circ}\right)$ :

$E_{\mathrm{k}}(t)=1.57\left(R^{\circ} / b\right)\left(R / R^{\circ}\right)^{3}$

Based on this model, a reduction of the effective pore size by a factor of 2 requires a decrease in the permeability by a factor of 100 for the $\gamma$ alumina membrane with $\left(R^{\circ} / b\right)=0.06$. This model can explain why for the $\gamma$-alumina membrane a substantial decrease in the permeability is required to achieve a small reduction in the effective pore size. These results and analysis suggest that in order to reduce the effective pore size of slit-shaped pores without an excessive decrease in porosity, the modification process should be conducted, if possible, under conditions that the pores are narrowed along the slit-width direction.

CVD of silica in the pores of $\mathrm{SiO}_{2}$ (glass) membranes with an average pore size smaller 
than $4 \mathrm{~nm}$ was performed by Okubo and Inoue [10] and Kito and Asaeda [13] with the aim to reduce the pore size or plugging pinholes (larger pores) of the membranes to improve permselectivity. The separation factor for $\mathrm{He} / \mathrm{N}_{2}$ was improved somewhat after modification, but the permeability for nitrogen decreased substantially. In the study of Okubo and Inoue [10] the PSD of the glass membrane appeared to become broader after modification. Ma et al. [12] reported the permeation data of permeability versus average pressure for helium through their $\gamma$-alumina membrane samples $(4 \mathrm{~nm}$ pore size) before and after deposition of metal oxides in the membrane pores. Apparently, values of $\left(\beta_{\mathrm{av}} / \alpha_{\mathrm{av}}\right)$ calculated from their permeation data for the $\gamma$-alumina membrane samples after modification are larger than those before modification, indicating an increase in the average pore size of these membrane samples after modification.

For UF ceramic membrane samples with pinholes or defects, the PSDs will exhibit a small portion of pores with a much larger pore size. For such UF ceramic membranes, the results of the theoretical analysis [23] suggest that the average pore size might increase with decreasing permeability. In modifying the silica membranes, the deposited silica may have plugged both the pinholes and the fine pores of the silica membranes. Thus, the modification may not result in a reduction in the average pore size, but cause a substantial decrease in the porosity (nitrogen permeability) as a result of closing the fine pores first. It should be noted that helium can permeate through the dense silica films (or silica plugs in the fine pores), which may explain the relatively small change in the helium flux in comparison with the substantial decrease in the nitrogen flux for the membranes after modification.

\section{Conclusions}

A simple gas permeation method based on measuring helium permeation flux through a membrane before and after modification was used to examine semi-quantitatively the change in the average pore size of ceramic membranes. The pore size change of an MF $\alpha$-alumina membrane and a UF $\gamma$-alumina membrane after CVD modification was investigated using gas permeation data. The CVD modification results in a reduction of the permeability by a factor of ca. 10 and 50 for the MF membrane and UF membrane, respectively. For both membranes, however, the average (effective) pore size does not decrease after such a modification under the conditions of the present experiments.

With a ca. 10-fold reduction in permeability, the average pore size of the MF membrane is found to increase after the CVD modification, due to its relatively broader initial pore size distribution with a small amount of larger pores and the particular CVD conditions (heterogeneous deposition mechanism) which give a pore narrowing rate independent of the pore size. The effective pore size of the UF membrane appears to remain unchanged after the modification with a ca. 50-fold reduction in permeability. The possible existence of pinholes in some of the UF membrane samples may be responsible for the increase in the average pore size observed for these samples after modification. For the MF and UF membranes studied and the CVD modification process under the investigated conditions, it is expected that the average (effective) pore size of these membranes will decrease only after a much more significant reduction in permeability.

The experimental and theoretical results suggest that in order to reduce effectively the average pore size of a membrane by a modification process, the membrane should have a rather uniform pore size distribution, or the modification process should be conducted under conditions which give a pore narrowing rate being proportional to the pore size. Otherwise, 
it is difficult to reduce the average pore size of the membrane by depositing solids in the membrane pores without a substantial decrease in permeability. The shape of the pores (slitshaped or circular) plays a role in selection of the modification conditions which lead to pore size decrease without an excessive reduction in porosity.

\section{List of symbols}

$E_{\mathrm{k}} \quad$ permeability reduction ratio (ratio of permeability after modification to that before modification)

$G$ pore narrowing rate $(\mathrm{m} / \mathrm{sec})$

$H \quad$ width of modification zone $(\mathrm{m})$

$J_{i}(R)$ flow of permeation gas through a pore with pore radius of $R$ ( $\mathrm{mol} / \mathrm{sec})$

$k$ pore narrowing kinetics constant $(\mathrm{m} / \mathrm{sec})$

$L$ thickness of a ceramic membrane (m)

$M \quad$ molecular weight of permeating gas (g/mol)

$P(R) \quad$ area pore size distribution function

$P_{\mathrm{av}} \quad$ average pressure across membrane $(\mathrm{Pa})$

$P_{\mathrm{h}} \quad$ pressure at upstream side in permeation measurement $(\mathrm{Pa})$

$P_{1} \quad$ pressure at downstream side in permeation measurement $(\mathrm{Pa})$

$P_{\mathrm{m}} \quad$ pressure at the interface between the modified zone and unmodified zone (Pa)

$Q$ flow of permeation gas ( $\mathrm{mol} / \mathrm{sec}$ )

$R$ pore radius (m)

$R_{\mathrm{g}} \quad$ gas constant

$R_{\mathrm{kv}} \quad$ flow-averaged pore radius of a membrane during modification ( $\mathrm{m}$ )

$R_{\mathrm{kv}}^{\circ} \quad$ flow-averaged pore radius of a membrane before modification ( $\mathrm{m}$ )

$\boldsymbol{R}^{\prime} \quad$ defined in eqn. (10)

$\boldsymbol{R}^{\prime \prime} \quad$ defined in eqn. (11)

$S_{i}(R)$ cross-sectional area of each pore with pore radius $R\left(\mathrm{~m}^{2}\right)$
$S_{\mathrm{po}} \quad$ total pore opening area of a membrane sample $\left(\mathrm{m}^{2}\right)$

$S_{\text {to }} \quad$ total cross-sectional area of a membrane sample $\left(\mathrm{m}^{2}\right)$

$T$ temperature (K)

Greek

$\alpha \quad$ permeation coefficient contributed by the Knudsen diffusion, eqn. (2) (mol/ $\mathrm{Pa}-\mathrm{m}^{2}-\mathrm{sec}$ )

$\beta \quad$ permeation coefficient contributed by the viscous flow, eqn. (2) $\left(\mathrm{mol} / \mathrm{Pa}^{2}\right.$ $\mathbf{m}^{2}$-sec)

$\Phi$ ratio of the pore size for modified zone after modification to that before modification

$\tau$ tortuosity factor for membrane

$\epsilon$ membrane porosity (ratio of pore opening area to the total membrane area)

$\alpha_{\mathrm{av}} \quad$ coefficient $\alpha$ for whole membrane sample (modified zone and unmodified zone) ( $\left.\mathrm{mol} / \mathrm{Pa}-\mathrm{m}^{2}-\mathrm{sec}\right)$

$\beta_{\mathrm{av}} \quad$ coefficient $\beta$ for whole membrane sample (modified zone and unmodified zones) ( $\left.\mathrm{mol} / \mathrm{Pa}^{2}-\mathrm{m}^{2}-\mathrm{sec}\right)$

$\alpha_{\mathrm{s}} \quad$ coefficient $\alpha$ for unmodified zone (support) (mol/Pa-m ${ }^{2}$-sec)

$\beta_{\mathrm{s}} \quad$ coefficient $\beta$ for unmodified zones (support) (mol/ $\mathrm{Pa}^{2}-\mathrm{m}^{2}$-sec)

$\alpha_{\mathrm{t}} \quad$ coefficient $\alpha$ for modified zone (toplayer) ( $\mathrm{mol} / \mathrm{Pa}-\mathrm{m}^{2}$-sec)

$\beta_{\mathrm{t}} \quad$ coefficient $\boldsymbol{\beta}$ for modified zone (toplayer) $\left(\mathrm{mol} / \mathrm{Pa}^{2}-\mathrm{m}^{2}\right.$-sec $)$

$\mu \quad$ viscosity of permeating gas (poise)

\section{References}

1 A.J. Burggraaf and K. Keizer, Synthesis of inorganic membranes, in R.R. Bhave (Ed.), Inorganic Membranes, Von Nostrand Reinhold, New York, NY, 1991, Chap. 2, pp. 10-63. 
2 R.A. Terpstra, B.C. Boekamp and H.J. Veringa, Preparation, characterization and some properties of tubular alpha alumina ceramic membranes for microfiltration and as support for ultrafiltration and gas separation membranes, Desalination, 70 (1988) 395.

3 R.J. Uhlhorn, K. Keizer and A.J. Burggraaf, Synthesis and gas separation properties of microporous membranes, J. Membrane Sci., 66 (1992) 271.

4 J.D. Way and D.L. Robert, Hollow fiber inorganic membranes for gas separations, Sep. Sci. Technol., 27 (1992) 29.

5 A.F.M. Leenaars, K. Keizer and A.J. Burggraaf, Microstructural investigations on non-supported membranes, J. Mater. Sci., 19 (1984) 1077.

6 M.A. Anderson, M.J. Gieselmann and Q. Xu, Titania and alumina membranes, J. Membrane Sci., 39 (1988) 243.

7 A. Larbot, J.-P. Fabre, C. Quizard and L. Cot, New inorganic ultrafiltration membranes: titania and zirconia membranes, J. Am. Ceram. Soc., 72 (1989) 257.

8 R.J.R. Uhlhorn and A.J. Burggraaf, High permselectivity of microporous silica-modified $\gamma$-alumina membranes, J. Mater. Sci., 8 (1989) 1135.

9 G.R. Gavalas, C.E. Megiris and S.W. Sam, Deposition of $\mathrm{H}_{2}$-permselective $\mathrm{SiO}_{2}$ films, Chem. Eng. Sci., 44 (1989) 1982.

$10 \mathrm{~T}$. Okubo and H. Inoue, Introduction of specific gas selectivity to porous glass membranes by treatment with tetraethoxysilane, J. Membrane Sci., 42 (1989) 109.

11 J.R. Miller and W.J. Koros, The formation of chemically modified $\gamma$-alumina microporous membranes, Sep. Sci. Technol., 25 (1990) 1257.

12 Y.H. Ma, Y.L. Becker, W.R. Moser and A.G. Dixon, Effect for catalyst impregnation on the transport properties of porous alumina membranes, Proc. 2nd Int. Conf. Inorg. Mem., Key Engineering Materials, Vols. $61 \& 62$, A.J. Burggraaf, J. Chapin and L. Cot (Eds.), Trans Tech Publications, Switzerland, 1991, pp. 337-346.

13 S. Kitao and M. Asaeda, Gas separation performance of thin porous silica membrane prepared by sol-gel and CVD methods, Proc. 2nd Int. Conf. Inorg. Mem., Key Engineering Materials, Vols. 61 \& 62, A.J. Burggraaf, J. Chapin and L. Cot (Eds.), Trans Tech Publications, Switzerland, 1991, pp. 267-272.

14 Y.S. Lin and A.J. Burggraaf, CVD of solid oxides in porous substrates for ceramic membrane modification, AIChE J., 38 (1992) 445.

15 Y.S. Lin and A.J. Burggraaf, Preparation and characterization of high temperature thermally stable alumina membrane composite, J. Am. Ceram. Soc., 74 (1991) 219.
16 C.L. Lin, G.R. Gallaher, R.R. Bhave, D.F. Flowers and P.K.T. Liu, Review on potential improvement of commercial microporous ceramic membrane for gas and liquid separation, Paper presented at 2nd Int. Conf. Inorg. Membrane, Montpellier, France, July 36, 1991.

17 C.L. Lin, D.F. Flowers and P.F.T. Liu, Characterization and performance evaluation of modified commercial ceramic membranes, Paper No. 7B, 5th Annual meeting of North American Membrane Society. Lexington, KY, May 17-20, 1992.

18 R.J. Uhlhorn, V.T. Zaspalis, K. Keizer and A.J. Burggraaf, Synthesis of ceramic membranes. Part II. Modification of alumina thin films: reservoir method, J. Mater. Sci., 27 (1992) 538.

19 E.F. Vansant, Pore Size Engineering in Zeolites, Wiley and Sons, New York, NY, 1990.

20 M. Niwa and Y. Murakami, CVD zeolites with controlled pore-opening size, J. Phys. Chem. Solids, 50 (1989) 487.

21 A.0. Isenberg, Growth of refractory oxide by electrochemical vapor deposition (EVD) at elevated temperature, in: J.D.E. McIntyre, S. Srinavasan and F.G. Will (Eds.), ECS Symp. Electrode Materials, Processes for Energy Conversion and Storage, Electrochem Soc. Inc., Princeton, NJ, 77 (6) (1977) 572.

22 T.M. Besmann, R.A. Lowden, B.W. Sheldon and D.P. Stinton, Chemical vapor infiltration, Proc. 11th Int. Conf. CVD, ECS Symp., Vol. 90 (12) (1990) 482-91.

23 Y.S. Lin, A theoretical analysis on pore size change of porous ceramic membranes after modification, J. Membrane Sci., 79 (1993) 55-64.

24 G.D. Parfitt and K.S.W. Sing (Eds.), Characterization of Powder Surface, Academic Press, London, 1976, Chap. 1, pp. 1-56.

25 E.J. Grosgogeat, J.R. Fried, R.G. Jenkins and S.-T. Hwang, A method for the determination of the pore size distribution of molecular sieve membranes and its application to the characterization of partially pyrolyzed polysilastyrene/porous glass composite membranes, J. Membrane Sci., 57 (1991) 237.

26 D.E. Fain, A dynamic flow-weighted pore size distribution, Proc. 1st Int. Conf. Inorg. Membranes, L. Cot and J. Charpin (Eds.), Refion Languedoc Roussilon, Montpellier, France, 1989, pp. 199-205.

27 F.P. Cuperus, Characterization of ultrafiltration membranes, Ph.D. Thesis, University of Twente, Enschede, The Netherlands, 1990.

28 E.A. Mason and A.P. Malinauskas, Gas Transport in Porous Media: 'The Dusty-Gas Model, Elsevier, Amsterdam, 1983, Chap. 2, pp. 11-72.

29 R.J.R. Uhlhorn, M.H.B.J. Huis in't Veld, K. Keizer and A.J. Burggraaf, Synthesis of ceramic membranes. Part I. Synthesis of non-supported and supported $\gamma$ - 
alumina membrane without defects, J. Mater. Sci., 27 (1992) 527.

30 Y.S. Lin, P. Fransen, K.J. de Vries, H.W. Brinkman and A.J. Burggraaf, Experimental study on CVD modification of ceramic membranes, Proc. 11th Int. CVD Conf., K.E. Spear and G.W. Cullen (Eds.), ECS Symp. Ser., 90(12) 1990, pp. 539-45. 